\title{
Encontros e Desencontros Críticos com a Modernidade Na Poesia Portuguesa Contemporânea
}

\author{
Ida Maria Santos Ferreira Alves (UFF)
}

\begin{abstract}
RESUMO: Trata-se de apresentar na poesia portuguesa do final do século XX uma perspectiva acentuadamente crítica das práticas diversas que forjaram a modernidade estética portuguesa, estabelecendo-se escritas inquietas e insubmissas. Com um discurso de confronto para compreensão dos mecanismos da tradição e com uma prática de deslocamento das linguagens dominantes, poetas como Joaquim Manuel Magalhães, João Miguel Fernandes Jorge, Nuno Júdice e Adília Lopes dialogam na tensão entre presente e passado cultural, sacralização e dessacralização da poesia, entre a cultura de língua portuguesa e a cultura globalizada e massificadora, interrogando na própria prática do poema o lugar crítico da poesia no mundo contemporâneo.
\end{abstract}

PALAVRAS-CHAVE: poesia portuguesa contemporânea; modernidade; crítica poética

ABSTRACT: This work presents a sharply critical perspective about aesthetic portuguese modernity in a piece of portuguese poetry from the late 20th century. The confrontation with the tradition and the practice of dominant languages transference. Brief reflection about the poets Joaquim Manuel Magalhães, João Miguel Fernandes Jorge, Nuno Júdice and Adília Lopes, who dialogue in strain between cultural present and past, sanctificiation and desecration of poetry, between the portuguese language culture and the globalized and mass influencing culture. The practice of the poem and the critical place of poetry in the contemporary world.

KEYWORDS: contemporary portuguese poetry; modernity; poetic criticism.

Segundo Eduardo Lourenço, em $O$ Labirinto da Saudade, obra hoje mais do que consagrada por suas reflexões sobre a cultura e a literatura portuguesa, “...a tradição não é essa continuidade [da inércia], é a assunção inovadora do adquirido, o diálogo ou combate no interior dos seus muros, sobretudo uma filiação interior criadora, fenômeno entre todos raro e insólito na cultura portuguesa" (1978: 76-77). Ora, a linguagem poética contemporânea (décadas de 70 a 90), em Portugal, comprova que essa "assunção inovadora do adquirido" não é "fenômeno raro e insólito", mas o resultado visível de práticas contínuas e acentuadamente críticas dos tempos diversos que forjaram a modernidade estética portuguesa. 
Se, com efeito, constatamos nessa produção a ausência de discursos radicais de ruptura como os propostos no auge dos projetos modernistas / vanguardistas das primeiras décadas do século XX, há decididamente uma vontade de confronto que deseja compreender e avaliar os mecanismos de uma tradição de modernidade e como esta pode ser deslocada, criando-se dobras críticas da própria cultura estética que a estabeleceu.

Quando falamos de tradição, nomeamos, a partir de uma perspectiva simplificadora, um conjunto de procedimentos e concepções do passado que chegam ao presente. Essa ligação temporal pode se realizar de formas diferentes, ou seja: a) o discurso do presente pode confirmar o do passado e tomá-lo como paradigma, impondo a continuidade passiva, a inércía, numa relação parafrástica; b) o discurso do presente pode rejeitar o do passado e buscar construções originais, numa prática vanguardista; c) o discurso do presente pode retomar o do passado e exercer sobre ele uma ação interrogativa, cruzando perspectivas, estabelecendo novas conexões, demonstrando diferenças, chegando ao novo a partir da transformação do "adquirido", numa ação dialógica. Seja qual for o caminho escolhido, não podemos negar o óbvio: o discurso do presente inevitavelmente deverá se confrontar com o do passado, a ruptura com a tradição, pois uma categoria só tem sentido em relação à outra, como já discutiu Otavio Paz (1984) sobre a tradição da modernidade e suas contradições.

Ora, em poesia, essa problemática parece ser especialmente visível quando é uma linguagem interrogativa sobre sua própria tradição, já que é trabalho verbal sempre atento às configurações de sentidos, às estruturas lingüísticas utilizadas e às realizações poemáticas estabelecidas ao longo do tempo. Pense-se, como um exemplo, esta forma que é o soneto, forma clássica que ainda é continente apreciável de muita poesia contemporânea. Também a respeito disso, escreveu Joaquim Manuel Magalhães, poeta e crítico português: "A poesia [...] é uma globalidade em contínua reformação a partir sempre do todo da literatura que lhe é tradição, de tal forma que em cada poema a globalidade da poesia está em jogo, bem como o próprio devir da poesia a partir desse poema. A tradição poética adquire, sobre o solo dos produtos já existentes, produtos novos que serão o solo de novos produtos e assim por diante" (1982: 28).

Na poesia portuguesa do século $\mathrm{XX}$, a discussão da relação entre diferentes tempos discursiva é fonte de escritas inquietas e insubmissas. Isso começou a ganhar unidade na cultura portuguesa do final do século XIX, quando os diversos níveis da sociedade se defrontaram com uma realidade muito afastada da idealidade histórica desejada e com novos paradigmas estéticos, destacadamente os franceses. $\mathrm{O}$ resultado desse confronto, sem dúvida, provocou, no âmbito literário, a obra de um Cesário Verde, a modernidade de Orpheu e a obra multiforme de Fernando Pessoa, que soube, como nenhum outro em seu tempo (mas talvez Almada Negreiros deva ser lembrado aqui...), instalar-se criticamente na tradição para causar rupturas em diversos níveis, mudando para sempre a face da poesia portuguesa moderna e estabelecendo uma outra fortíssima tradição: a 
do fingimento, com seu pensar / sentir, que ainda hoje, em novo século, ecoa na escrita literária portuguesa.

No caso da poesia que se começa a publicar na década de 70 , conhecedora não só da tradição poética ocidental como especialmente da tradição da modernidade e suas aporias, busca-se definir uma fronteira crítica atenta ao lugar do poético em nosso tempo de incertezas. Já não adianta negar uma tradição e, sim, situar-se nela, dominar seus meios de atuação e, a partir desse domínio, demonstrar as lacunas dos discursos. Assim, a leitura das obras poéticas de poetas como Joaquim Manuel Magalhães, João Miguel Fernandes Jorge, Nuno Júdice e Adília Lopes, por exemplo, encontram-se no mesmo lugar crítico sobre o poético, com perguntas semelhantes: por quê ou para quê escrever ainda hoje? Como ler a literatura os formou? Que cultura é essa que os cerca? Como falar deste tempo contemporâneo, presente de um passado que não se pode esquecer? As obras desses poetas, para além dos diferentes caminhos que seguem, encontram-se nessa tensão entre o presente e o passado, entre a Literatura como Instituição e a escrita literária dessacralizada e dessacralizadora, entre uma cultura em língua portuguesa e um mundo globalizado e massificado. Por isso, são poetas-críticos de seu tempo a interrogar a Poesia, a Cultura, a História e a constituição da subjetividade / identidades no texto e na sociedade contemporânea. Em traços largos, podemos delinear certas práticas determinantes. Uma é questionar o próprio discurso literário, desconstituindo a palavra sacralizada e expondo sua ruína em nossa contemporaneidade, quando o literário tornou-se intensivamente um produto de mercado, uma questão de consumo a envolver escritores, leitores e críticos. Com linguagem irônica e, muitas vezes, melancólica, os poetas se negam a compactuar com as regras do mercado ou a reduzir a escrita poética a prato de fácil degustação. Ou ironicamente, defendem um regresso ao sentido, uma conquista de leitores pela frugalidade da experiência cotidiana. Dessa visão é prova a escrita de Joaquim Manuel Magalhães, poeta que exerceu, no âmbito da geração de 70 e de 80 , uma função debatedora de grande alcance:

como vou saber se a diferença não há-de ser um pacto novo, um regresso às histórias e às árduas gramáticas da preservação.

[...] voltar à ordem das mágoas por uma linguagem limpa, um equilíbrio do que se diz ao que se sente, um ímpeto ao ritmo da língua e dizer / a catástrofe pela articulada afirmação das palavras comuns, o abismo pela sujeição às formas directas do murmúrio, o terror pela construída sintaxe sem compêndios. Voltar ao real, a esse desencanto que deixou de cantar. (1974: 13) 
Essa perspectiva crítica está igualmente no prefácio assinado por Manuel de Freitas numa pequena antologia intitulada Poetas sem qualidades (2002), em que se defende uma poesia do mais simples, sem sublime ou meditação, uma banalização da palavra poética, a rarefação de uma tradição portuguesa de alto lirismo. Vale a citação mais longa:

O que, de alguma maneira, aproxima estes nomes (e legitimará, porventura, reuni-los num mesmo livro) são, precisamente, as várias 'qualidades' que notoriamente não possuem. Estes poetas não são muita coisa. Não são, por exemplo, ourives de bairro, artesãos tados-mallarmeanos, culturalizadores do poema digestivo, parafraseadores de luxo, limadoes das arestas que a vida deveras tem. Podemos, pelo contrário, encontrar em todos eles um sentido agónico (discretíssimo, por vezes) e sinais evidentes de perplexidade, inquietação ou escárnio perante o tempo e o mundo em que escrevem. Não serão, de facto, poetas muito retóricos (embora à retórica, de todo, se não possa fugir), mas manifestam força - ou admirável fraqueza - onde outros apenas conseguem ter forma ou uma estrutura anémica. Comunicam, em suma; não pretendem agradar ou ser poeticamente correctos. Só é possível falar destes poetas negativamente (e ainda bem): aproxima-os a falta de todas essas qualidades em que os seus contemporâneos se têm revelado pródigos. Por isso estão aqui, a desabrigo, a dizer o que dizem.

Por outro lado, acreditando, apesar de tudo, que a Arte é a garantia da nossa humanidade, há ainda aqueles poetas que refletem sobre seu papel de resistência e fazem dialogar as diversas artes. Buscam a intertextualidade crítica para figurar uma comunidade estética que lhes faça compreender melhor a própria razão de sua escrita e da cultura que os formou. Isso, por exemplo, é uma das direções da poesia de Nuno Júdice, retomando autores clássicos, românticos, simbolistas e modernos, num diálogo inquiridor do "próprio poético". Muitos poemas poderiam ser citados, mas registremos apenas uma estrofe do poema "Lugones", em Meditação sobre Ruínas: "Só a poesia inspira a poesia, / como in vino veritas; / se a metáfora varia / as imagens são pretéritas" (1995: 22).

Outros poetas ainda avaliam a idéia de tradição como passado consagrado e, por isso, recontam a História para estabelecer diferenças e não permitir a imposição de sentidos. Rever criticamente a História é, sem dúvida, um trajeto que recebe especial atenção no panorama da poesia portuguesa contemporânea, já que Portugal vivenciou uma História quinhentista gloriosa e a traumática perda dessa imagem, criando-se um vazio de identidade que, no século XX, com o peso de cinquënta anos de ditadura, acentuou o pessimismo e a melancolia em relação a ser português. Citemos, como exemplo, poetas como João Miguel Fernandes Jorge a recuperar as crônicas históricas de Fernão Lopes e a cruzá-las com o tempo presente, Fernando Assis Pacheco a fazer a crônica da guerra colonial (leia-se o livro Catalabanza, Quilolo e Volta (1976) e nele o poema "A Epopéia” ), Al Berto nos seus livros, Salsugem (1984) e Três Cartas da Memória das Índias (1985) e no conjunto de poemas dedicados a Lisboa em Horto de Incêndio 
(1997). Esses e outros que aqui poderiam ser citados revêem os discursos de uma tradição histórica esgotada e evidenciam rompimentos, fissuras e simulacros.

Também outros poetas questionam o sujeito poético, numa tradição pessoana, discutindo seu lugar na contemporaneidade e o modo como pode se constituir na linguagem. Isso significa não só repensar a subjetividade, a emotividade e as máscaras do poeta, como também desvelar o sujeito oculto na margem, principalmente numa vivência amorosa que não mais corresponde à tradição romântica ou idealista do amor. Assim é recorrente nessa poesia a afirmação mais contudente do discurso homoerótico, enfrentando não só uma tradição social portuguesa como também uma tradição lírica em que o sujeito amoroso se direciona ao feminino ou ao divino. Agora o amigo é claramente o objeto desejado, e a relação amorosa uma desconstrução de imagens. Escreve Joaquim Manuel Magalhães :

Encontramos um amigo numa fonte

a água foge nos seus dedos, falamos-lhe.

Pomos a boca sobre a fria superfície

da sua pele onde bate o sol,

uma eira incendiada de folhas.

O coração cresce debruçado

para os seus olhos caídos contra nós.

Tem um sorriso, uma camisa aberta,

o peito um arco de respiração.

Lentamente afasta-se. As suas mãos

nenhuma noite bastará.

A fonte secou, o caminho que seguimos foi devorado.

Na manhã os pássaros começam a sangrar. (1987: 75)

Mas, neste rápido panorama, devemos destacar o trabalho de encontro e desencontro com a modernidade que a escrita de Adília Lopes, com certa recepção brasileira no eixo Rio de Janeiro -São Paulo, vem realizando desde o final da década de 80, com uma escrita dissolvente que afronta os paradigmas literários, sociais e culturais, com aparente ênfase na paródia, no cômico e non-sense. Numa escrita que se vale da sintaxe mais rala, numa poética que se diz do lixo, temos um mosaico de citações, de referências literárias, de jogos de linguagem que corroem os textos literários alheios, constituindo uma desleitura nada inocente por trás da aparente infantilidade e fragilidade de seus versos:

"Acabou

o tempo

das rupturas

Quero

ser

reparadora

de brechas (2006: 24) 
ou o poema "Para Rimbaud":

O I é encarnado

é vermelho

ruge

como o leão

range

como a madeia

grita

como a mulher

a parir

Ir

ira

Iraque

(quando mudei de Física para Românicas, o Professor Pinto Peixoto disse-me que eu ia para a Faculdade de Letras contar quantos "ques" tem a Peregrinação e ensinar às minhas colegas o que é entropia) (2006: 37)

Temos, então, nessa diversidade da poética portuguesa contemporânea, escritas que não mais acreditando em "vanguardas", vasculham as "retaguardas" em busca do que foi silenciado ou rasurado, reapresentando a modernidade com o olhar crítico sobre as tradições diferenciadas e rupturas experimentadas. Busca-se não simplesmente assumir "filiações interiores criadoras", mas avaliá-las, transformá-las, constituindo discursos em deslocamento, deslocamento de processos e de efeitos modernos.

\section{OBRAS CITADAS}

AMARAL, Fernando Pinto do. 1991. O mosaico fluido - modernidade e pósmodernidade na poesia portuguesa mais recente. Lisboa: Assírio \& Alvim, 1991.

FREITAS, Manuel de. 2002. poetas sem qualidades. Averno.

JUDICE, Nuno. 1995. Meditação sobre ruínas. Lisboa: Quetzal.

LOPES, Adília. 2002. Antologia. Rio de Janeiro: 7 Letras /Cosac \& Naify. 2006. Le vitrail la nuit - a árvore cortada. Lisboa: \&etc.

LOURENÇO, Eduardo. 1988. O labirinto da saudade. 3. ed. Lisboa: Dom Quixote.

MAGALHÃES, Joaquim Manuel. 1981. Os dois crepúsculos - sobre poesia portuguesa actual e outras crónicas. Lisboa: A Regra do Jogo.

1982. Dylan Thomas consequência da literatura e do real na sua poesia. Lisboa: Assírio e Alvim. 
1987. Alguns livros reunidos. Lisboa: Contexto.

MARTELO, Rosa Maria Martelo. 2004. Em parte incerta - estudos de poesia portuguesa moderna e contemporânea. Porto: Campo das Letras.

PAZ, Otavio. 1984. Os filhos do barro. Rio de Janeiro: Nova Fronteira. 